\title{
Drying of sugarcane bagasse in a partially filled horizontal drum
}

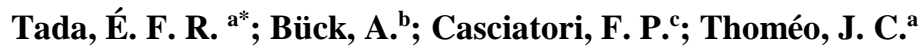

${ }^{a}$ Department of Food Engineering and Technology. Institue of Biosciences, Humanities and Exact Sciencies. São Paulo State University, São José do Rio Preto, Brazil

b Institute of Particle Technology. Friedrich-Alexander University Erlangen-Nuremberg, Erlangen, Germany.

${ }^{\mathrm{c}}$ Chemical Engineering Department, Center of Exacts Sciences and Technology. São Carlos Federal University, São Carlos, Brazil.

*E-mail of the corresponding author: erikartada@gmail.com

\begin{abstract}
One-phase model have been reported to describing the simultaneous heat and mass transfer in a horizontal drum partially filled by sugarcane bagasse with attention to the loss of water promoted by the increase of temperature. Mass and energy balances were written in MatLab language and solved by finite difference method. Predicted temporal and spatial profiles of moisture content and temperature are shown. Experimental tests were carried out in a horizontal drum and the temporal profiles were obtained. Great adjustments between experimental and predicted data were observed, indicating that the model is able to describe the transport phenomena in this system.
\end{abstract}

Keywords: horizontal drum; heat and mass balances; sugarcane bagasse; solid-state fermentation process. 


\section{Introduction}

Rotary drums are widely employed in several industrial processes involving particulate systems. Specifically in solid-state fermentation processes, the use of rotary drum bioreactors have been investigated because these equipments offer more mechanisms to control of operational conditions during the fermentation process [1].

Solid-state fermentation (SSF) is a prodigious technology that it enables the obtention of high-value compounds from solid cultive of microorganisms in wet agro-industrial residues [2], as such the fibers of sugarcane bagasse [3]. Promissors results have been reported by literature in laboratorial scale on the yield of compounds through FES [4]. However, the industrial scale yet is not available to use due to difficulties related to scale-up of bioreactors for FES, such as the undesirable increases of temperature during the process. Considering the use of rotation in intermittent regime as a mechanism of heat removal, the particles bed keeps static during long periods and then are periodically moved. This allows tha analysis of this process from a static bed in a horizontal drum.

The increase in the temperature observed during SSF process can promote other phenomena that deserve attention, such as the loss of water in heated regions of the bed. The recent literature has reported that the moisture content of the organic particles is directly related to bed properties as porosity and efficient thermal conductivity [5,6]. Fundamental studies have been reported about the no-reactional particulate systems in geometries similar to bioreactors and are important to understand some aspects about transport phenomena in these systems [7,8]. In this context, this work aims the proposition of heat and mass balances to descrive the temperature and water profiles in a partially filled horizontal drum by a sugarcane bagasse bed, in attention to possible water remotion due to increases on the temperature.

\section{Materials and Methods}

\subsection{Phsysical situation}

The physical situation in this case study is presented in Fig. 1. The horizontal drum was built in stainless stell and has $10 \mathrm{~cm}$ of inner dimeater and $20 \mathrm{~cm}$ of length. The inner wall of the drum was kept at constant temperature $\left(45^{\circ} \mathrm{C}\right.$ or $\left.65{ }^{\circ} \mathrm{C}\right)$ and the bed was initially at $25^{\circ} \mathrm{C}$. The bed was continually heated by heat penetration through of the wall and the water removal occurried simultaneously as a response to increases in the temperature. The fibers of sugarcane bagasse were employed at $3 \mathrm{~kg}$-water/kg-dried solid, which is corresponding to the operational condition for a solid-state fermentation process [3,9]. 


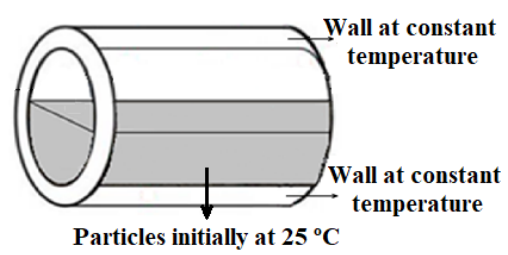

Fig. 1. Physical situation to verify the water removal in a partially filled horizontal drum due to increase in the temperature.

\subsection{Mathematical model}

A one-dimensional and one-phase model was proposed to describing the temporal and spatial temperature and water profiles in a partially filled horizontal drum. The water balance is shown in Eq. (1). In this equation, the first therm of left hand represent the temporal variation of water in the bed, the first therm of the right hand represent the spatial variation of water in the radial direction and the last term represent the water removal due to increase in the temperature. In this term, it was assumed that the moisture of the particles was carried by the air amidst the porous bed. The air was continuously heated and it described radial flow thorugh of the bed with velocity $V_{r}$.

$$
\frac{\partial \mathrm{X}}{\partial \mathrm{t}}=\mathrm{D}_{\text {eff }}\left[\frac{1}{\mathrm{r}} \frac{\partial \mathrm{X}}{\partial \mathrm{r}}+\frac{\partial^{2} \mathrm{X}}{\partial \mathrm{r}^{2}}\right]+\frac{\rho_{\mathrm{a}}}{\rho_{\mathrm{s}}} \mathrm{V}_{\mathrm{r}} \mathrm{f} \frac{\mathrm{dT}}{\mathrm{dr}}
$$

The energy balance is shown in Eq. (2).

$$
\rho_{\mathrm{b}} \mathrm{Cp}_{\mathrm{b}} \frac{\partial \mathrm{T}}{\partial \mathrm{t}}=\mathrm{K}\left[\frac{1}{\mathrm{r}} \frac{\partial \mathrm{T}}{\partial \mathrm{r}}+\frac{\partial^{2} \mathrm{~T}}{\partial \mathrm{r}^{2}}\right]+\left[\left(\mathrm{Cp}_{\mathrm{a}}-\lambda \mathrm{f}\right) \rho_{\mathrm{a}} \mathrm{V}_{\mathrm{r}} \frac{\partial \mathrm{T}}{\partial \mathrm{r}}\right]
$$

The initial and boundary conditions are shown in Eqs. (3) to (8).

$$
\begin{array}{l|l}
\mathrm{t}=0, & \begin{array}{l}
\mathrm{T}=\mathrm{T}_{0} \\
\mathrm{X}=\mathrm{X}_{0}
\end{array} \\
\mathrm{r}=\mathrm{r}_{\mathrm{i}(\theta)}, & \mathrm{K} \frac{\partial \mathrm{T}}{\partial \mathrm{r}}=-\alpha\left(\mathrm{T}-\mathrm{T}_{\infty}\right) \\
& \mathrm{D}_{\text {eff }} \frac{\partial \mathrm{X}}{\partial \mathrm{r}}=-\beta\left(\mathrm{X}-\mathrm{X}_{\mathrm{eq}}\right)
\end{array}
$$




$$
\begin{array}{l|l}
\mathrm{r}=\mathrm{R}, & \mathrm{T}=\mathrm{T}_{\mathrm{w}} \\
\mathrm{D}_{\text {eff }} \frac{\partial \mathrm{X}}{\partial \mathrm{r}}=0
\end{array}
$$

in which $r=r_{i(\theta)}$ is the superfitial position and $r=R$ represents the wall of the drum.

For the solution, the spatial variation were discretized by finite difference method. The resultant equations were written in MatLab ${ }^{\circledR}$ language and solved by ode15s for a geometry of a partially filled cincunference, as described by [8].

\subsubsection{Parameters of the model}

The effective diffusivity of the water through the bed have been experimentally determined by [10] as a function of the temperature. The effective thermal conductivity of sugarcane bagasse bed as a function of moisture content of the fibers was extracted from [5].

The coefficients $\alpha$ and $\beta$ were teorically estimed using correlations available in the literature for the parallel flow of a fluid above the surface of a rugous flat plate. The velocity $V_{r}$ was estimed using correlations for free convection through a packed-bed constituted by spherical particles.

\subsubsection{Simulations and verification of the model}

Simulations were carried considering the temperature of the wall $\left(\mathrm{T}_{\mathrm{w}}\right)$ at 45 or $65{ }^{\circ} \mathrm{C}$ and the temporal predicted profiles were compared with experimental profiles. The experimental tests were carried out in a jacketed horizontal drum (inner diameter: $10 \mathrm{~cm}$, length: $20 \mathrm{~cm}$ ). The inner wall of the drum was kept at 45 or $65{ }^{\circ} \mathrm{C}$ and the fibers of sugarcane bagasse were insered in the drum at $25^{\circ} \mathrm{C}$ and about $3 \mathrm{~kg}$-water/kg-dried solid in filling degree 0.5 . Samples of the bed were collected to determination of moisture content in a drying oven at $105^{\circ} \mathrm{C}$ until constant weight. The quality of adjustment was evaluated thorugh statistical indicators such as the coefficient of determination $\left(\mathrm{R}^{2}\right)$ and the root mean square error (RMSE).

\section{Results and Discussion}

The temporal mean temperature profiles for $\mathrm{T}_{\mathrm{w}}$ at 45 and $65^{\circ} \mathrm{C}$ are shown in Fig. 2. 
Tada, É. F. R.; Bück, A.; Casciatori, F. P.; Thoméo, J. C.

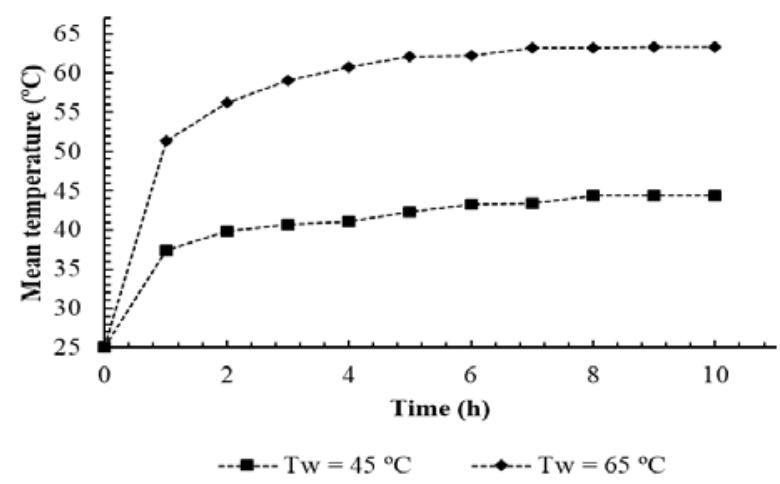

Fig. 2. Temporal mean temperature profiles of a sugarcane bagasse bed in a horizontal drum with temperature of the wall drum at 45 and $65^{\circ} \mathrm{C}$.

The temperature increases subtly in the first hour as reported by [11] for a bed compoused by dried fibers of sugarcane bagasse in this same horizontal drum. Discrete increase on the temperature were observed for the interval from 1 to 4 hours and the thermal equilibrium was obtained around $\mathrm{t}=4 \mathrm{~h}$ of process for all conditions. It indicates that the initial noisothermal problem becomes an isothermal problem along the time and it could be approximated and solved just through a mass balance for the equilibrium temperature in the interval from $\mathrm{t}=4 \mathrm{~h}$ to $\mathrm{t}=10 \mathrm{~h}$. The spatial moisture content profiles for $\mathrm{T}_{\mathrm{w}}$ at 45 and $65^{\circ} \mathrm{C}$ for $\mathrm{t}=1$ hour (on left hand) and 10 hours (on right hand) are shown in Fig. 3.
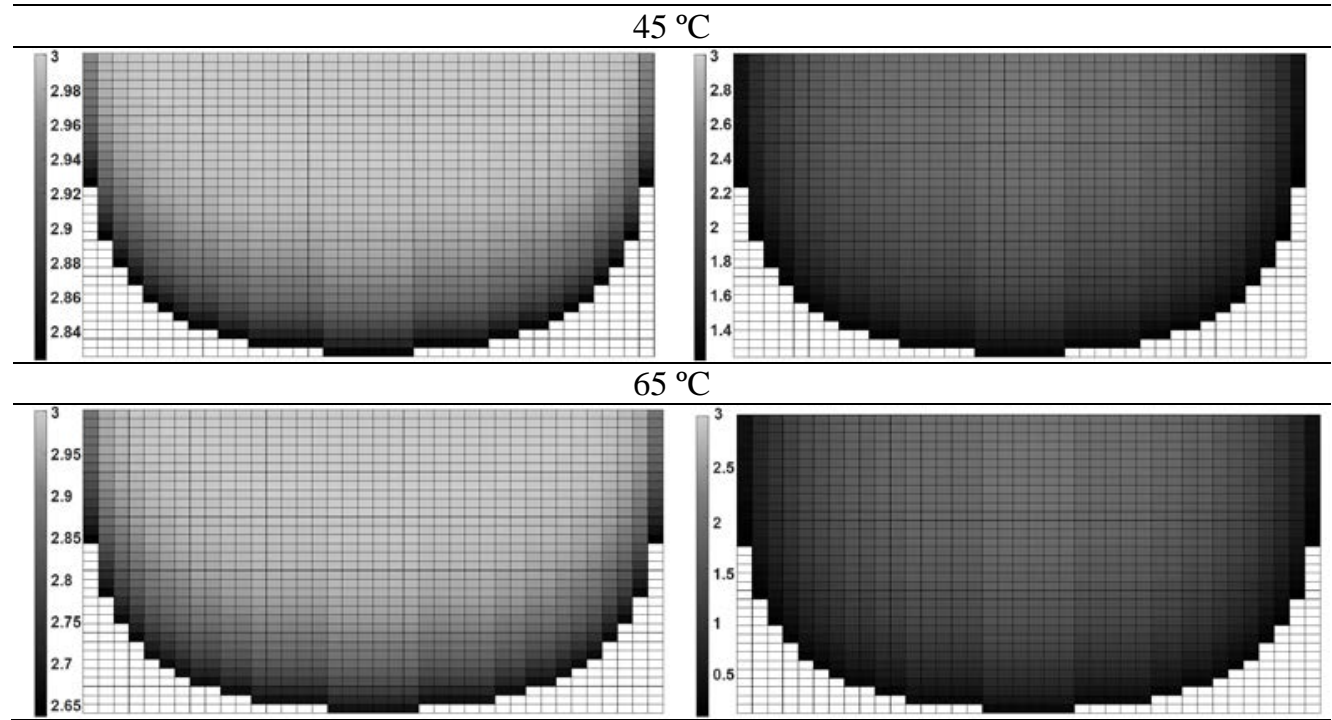

Fig. 3. Spatial moisture profiles ( $\mathrm{kg} / \mathrm{kg}-\mathrm{ds})$ of a sugarcane bagasse bed in a horizontal drum with temperature of the wall drum at 45 and $65^{\circ} \mathrm{C}$. 
The mass flux was observed in the radial direction from the wall to the surface of the bed. The presence of the air in the headspace promoted discrete variation on the moisture content in the surface of the bed because the air was partially satured on water vapor and its capacity to carry water was reduced. After 10 hours of process, the simulated profiles show that the system is near to the mass equilibrium.

The verification of the model is shown in Fig. 4 and 5 for the temperature and moisture profiles, respectively, for $\mathrm{T}_{\mathrm{w}}$ at 45 and $65{ }^{\circ} \mathrm{C}$. Good agreements were observed between experimental and predicted profiles and them were supported by statistical indicators $\left(\mathrm{R}^{2}>\right.$ 0,95 and RMSE < 0,62).

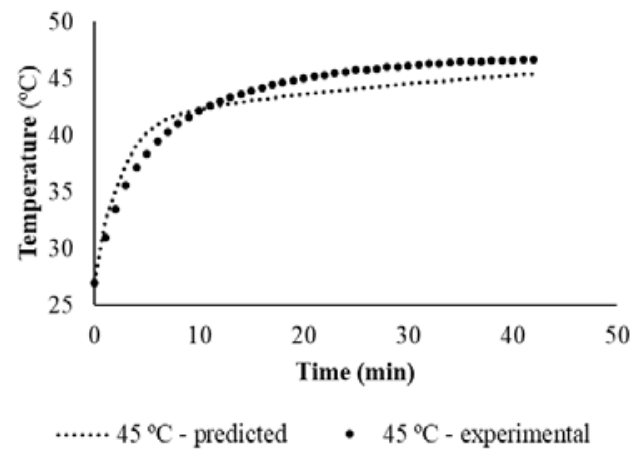

(a) $45^{\circ} \mathrm{C} ; \mathrm{R}^{2}=0.96 ; \mathrm{RMS}=0.21$

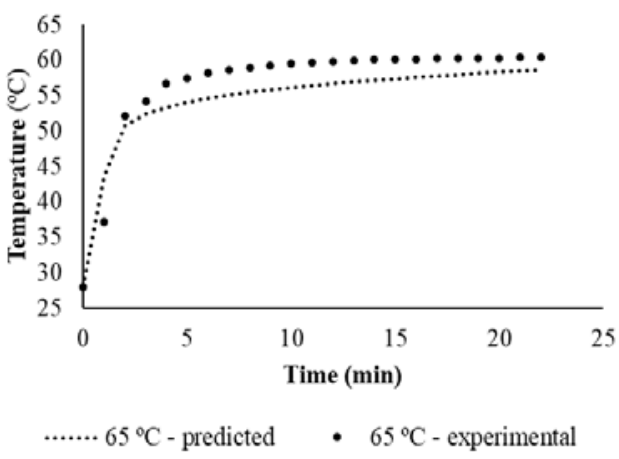

(b) $65^{\circ} \mathrm{C} ; \mathrm{R}^{2}=0.95 ; \mathrm{RMSE}=0.62$

Fig. 4. Predicted and experimental temperature profiles in a horizontal drum partially filled by fibers of sugarcane bagasse $\left(\mathrm{Tw}=45^{\circ} \mathrm{C}(\mathrm{a})\right.$ or $65^{\circ} \mathrm{C}(\mathrm{b})$; $\left.\mathrm{TO}=25^{\circ} \mathrm{C}\right)$.

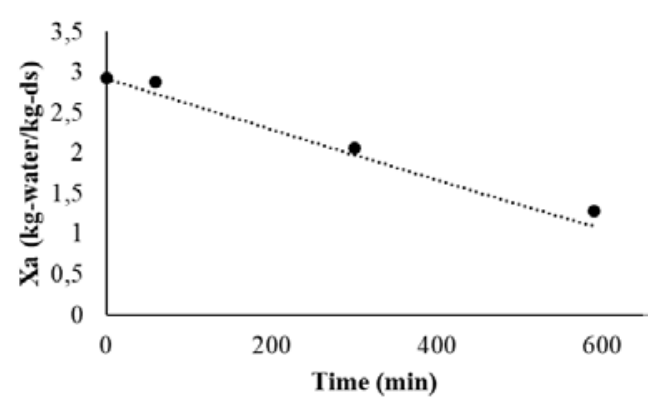

- $45^{\circ} \mathrm{C}$ - experimental $45^{\circ} \mathrm{C}$ - predicted



- $65^{\circ} \mathrm{C}$ - experimental $65^{\circ} \mathrm{C}$ - predicted

Fig. 5. Predicted and experimental moisture profiles in a horizontal drum partially filled by fibers of sugarcane bagasse $\left(\mathrm{Tw}=45^{\circ} \mathrm{C}(\mathrm{a})\right.$ or $65^{\circ} \mathrm{C}(\mathrm{b})$; $\left.\mathrm{TO}=25^{\circ} \mathrm{C}\right)$. 


\section{Conclusions}

The proposed model to describing the simultaneous heat and mass transfer in a sugarcane bagasse bed in a horizontal drum presented great adjustment with the experimental data $\left(\mathrm{R}^{2}\right.$ $\geq 0.95$ and $\mathrm{RMSE} \leq 0.62$ ) for temperatures of the drum wall at 45 and $65{ }^{\circ} \mathrm{C}$. The temporal temperature profiles shown that the thermal equilibrium is reached and the problem could be solved just through a isotherm mass balance. The loss of water in the regions near to the drum wall was visible in the spatial moisture profiles, indicating that the mass balance is sensible to increase in the temperature.

\section{Nomenclature}

$\begin{array}{lll}\text { Cp } & \text { specific heat } & \mathrm{J} \mathrm{Kg}^{-1} \mathrm{~K}^{-1} \\ \mathrm{D}_{\text {eff }} & \text { effective diffusivity } & \mathrm{m}^{2} \mathrm{~s}^{-1} \\ \mathrm{f} & \text { air capacity to carrier water } & \mathrm{Kg} \mathrm{Kg}^{-a i r}{ }^{-1} \\ \mathrm{~K} & \text { effective thermal conductivity } & \mathrm{W} \mathrm{m}{ }^{-1} \mathrm{~K}^{-1} \\ \mathrm{r} & \text { radial coordinate } & \mathrm{m} \\ \mathrm{t} & \text { time } & \mathrm{s}, \mathrm{min} \text { or h } \\ \mathrm{T} & \text { temperature } & { }^{\circ} \mathrm{C} \\ \mathrm{V} & \text { velocity } & \mathrm{m} \mathrm{s}^{-1} \\ \mathrm{X} & \text { moisture content in dried basis } & \mathrm{Kg} \mathrm{Kg-ds}^{-1}\end{array}$

Greek letters

$\begin{array}{llll}\alpha & \begin{array}{l}\text { convective } \\ \text { coefficient }\end{array} & \text { heat transfer } & \mathrm{W} \mathrm{m}^{-2} \mathrm{~K}^{-1} \\ \beta & \begin{array}{l}\text { convective } \\ \text { coefficient }\end{array} & & \\ \rho & \text { density } & & \\ \lambda & \text { latent heat of evaporation of } & \mathrm{J} \mathrm{Kg} \mathrm{s}^{-1} \\ & \text { water }\end{array}$

Subscripts

$\begin{array}{llrl}0 & \text { initial } & \mathrm{i}(\theta) & \text { surface } \\ \infty & \text { headspace } & \text { s } & \text { solid } \\ \text { a } & \text { air } & \text { r } & \text { radial } \\ & & & \text { direction }\end{array}$




$\begin{array}{llll}\text { b } & \text { bed } & \text { w } & \text { wall } \\ \text { eq } & \text { equilibrium } & & \end{array}$

\section{References}

[1] Durand, A. Bioreactor design for solid state fermentation bioreactors. Biochemical Engineering Journal 2003, 13, 113-125.

[2] Pandey, A. Solid-state fermentation. Biochemical Engineering Journal 2003, 13, 8184.

[3] Zanelato, A. I.; Shiota, V. M.; Gomes, E.; da Silva, R.; Thoméo, J. C. Endoglucanase production with the newly isolated Myceliophtora sp. I-1d3b in a packed bed solid state fermentor. Brazilian Journal of Microbiology 2012, 43, 1536-1544.

[4] Bhargav S.; Panda, B. P.; Ali, M.; Javed, S. Solid-state Fermentation: An Overview. Chemical and Biochemical Engineering 2008, 22(1), 49-70.

[5] Casciatori, F. P.; Laurentino, C. L.; Lopes, K. C. M.; Souza, G. A.; Thoméo, J. C. Stagnant effective thermal conductivity of agro-industrial residues for solid-state fermentation. International Journal of Food Properties 2013, 16(7), 1578-1593.

[6] Casciatori, F. P.; Laurentino, C. L.; Toboga, S. R.; Casciatori, P. A.; Thoméo, J. C. Structural properties of beds packed with agro-industrial solid by-products applicable for solid-state fermentation: Experimental data and effects on process performance. Chemical Engineering Journal 2014, 255, 214-224.

[7] Herz, F.; Mitov, I.; Specht, E.; Stanev, R. Experimental study of the contact heat transfer coefficient between the covered wall and solid bed in rotary drums. Chemical Engineering Science 2012, 82, 312-318.

[8] Tada, É. F. R.; Bück, A.; Casciatori, F. P.; Tsotsas, E.; Thoméo, J. C. Investigation of heat transfer in partially filled horizontal drums. Chemical Engineering Journal 2017, 316, 988-1003.

[9] Casciatori, F. P.; Bück, A.; Thoméo, J. C.; Tsotsas, E. Two-phase and twodimensional model describing heat and water transfer during solid-state fermentation within a packed-bed bioreactor. Chemical Engineering Journal 2016, 287, 103-116.

[10] Tada, É. F. R. Produção de celulases fúngicas por fermentação em estado sólido em tambor horizontal parcialmente preenchido: modelagem, simulação e experimentação. 2018. 100 f. Qualificação de Doutorado. Instituto de Biociências, Letras e Ciências Exatas, Universidade Estadual Paulista, São José do Rio Preto. In Portuguese.

[11] Bertucci, V. F.; Tada, É. F. R.; Thoméo, J. C. Modelagem e simulação de transferência de calor em tambor horizontal parcialmente preenchido com partículas orgânicas. In: Anais do XII Congresso Brasileiro de Engenharia Química em Iniciação Científica. São Paulo: Blucher, 2017. In Portugese. 